\title{
Research on support mode of Medium Altitude Long Endurance UAS based on the mode of military trade
}

\author{
Haoran Deng ${ }^{1,2, *}$, Zhenyu $\mathrm{Zhu}^{1,2}$, and Jianghui Wang ${ }^{1,2}$ \\ ${ }^{1}$ CH UAV Technology Co. Ltd, China \\ ${ }^{2}$ Academy of Aerospace Aerodynamics, China
}

\begin{abstract}
The Unmanned Aerial System (UAS) is more and more widely used in modern warfare, and its problem of support mode is becoming more and more prominent. The support mode of UAS refers to the standard mode to ensure the operation and maintenance of UAS which mainly composed of maintenance level, organization structure and contractor logistical support system. In most cases the support mode of UAS draws lesson from manned vehicles'. For the research and application of support model of UAS is relatively lagging, for example, the division of maintenance level is not clear; the allocation of support resources is redundant; military force lacks maintenance support capability; logistical support professional setting is not reasonable; the contractor logistics support system is not normative. So, there is no a set of effective, reasonable and normative support mode to support the operation and maintenance of UAS, resulting in the operational readiness of UAS is not high and maintenance process wastes a lot of manpower and material and money, which greatly restricts the operation and development of UAS. Combined with the UAS support requirements and features under the military trade, this paper analyses the status of the redundant and inefficient support mode. Aiming at these problem, a new support model of UAS will be researched from three aspects including the allocation of maintenance level, the adjustment of military maintenance organization structure, and the establishment of contractor logistical support system. By applying the new support mode to user, the operation and support of UAS will be more effective and reasonable which will greatly promote the development of UAS.
\end{abstract}

\section{Introduction}

The Unmanned Aerial System (UAS) is more and more widely used in modern warfare, and its position in the equipment systems is becoming more and more prominent. In many types of UAS, Medium Altitude Long Endurance (MALE) UAS outshine others and make brilliant victories in the war, which mainly responsible for the target indication, military mapping, battlefield reconnaissance, target surveillance, low speed or fixed target strike,

\footnotetext{
* Corresponding author: denghaoran0825@foxmail.com
} 
damage assessment, communication relay, electronic warfare, information attacks, targeted killings and so on. In the Gulf War, the Kosovo war, the Afghanistan war, the Iraq war and the war on terror, UAS demonstrate and verify its operational effectiveness. Many countries pay more and more attention to the effects of UAS on tactics and strategies in the war, purchase and develop the UAS as a key of future weapon system development.

The UAS of China's military trade export perform excellently in major battlefields and receive highly praised by the foreign countries. The $\mathrm{CH}$ UAS series developed by China have made brilliant combat success in the military actions involved in many countries in the Middle East. As the representative of the MALE UAS, the CH-4 UAS outfit and participate in the many wars. According to statistics, CH-4 UAS have flown more than 1000 sorties, and its flight time is over 5000 hours in total, which has become one of the indispensable foreign military equipment.

But the logistical support mode of UAS is more and more prominent, especially in support mode. The support mode of UAS includes maintenance level, organization structure and contractor logistical support system, as shown in figure 1.

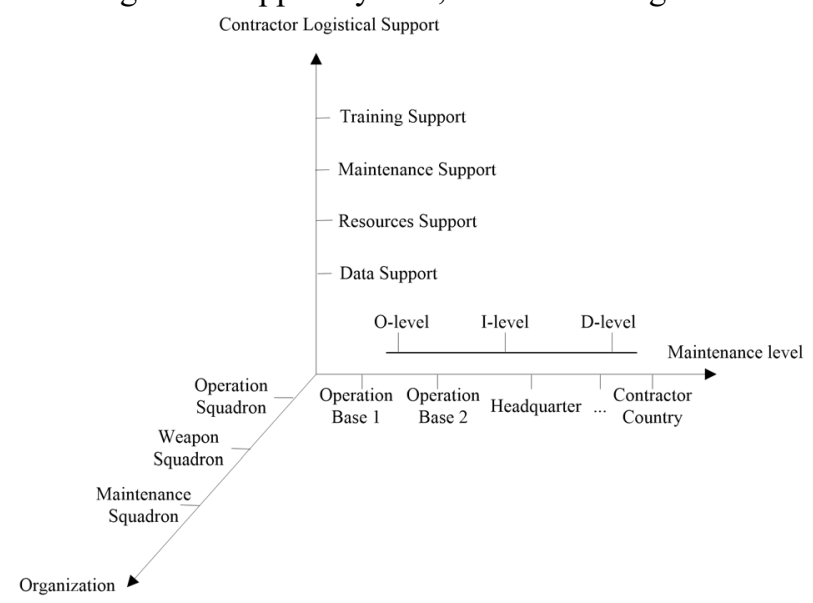

Fig. 1. Figure with the support mode of UAS.

Most of the support mode of UAS are based on the support mode of the manned aircraft. The research and application of support mode of UAS is relatively backward, for example, the division of maintenance level is not clear; military force lacks of maintenance support capability; support professional setting is not reasonable; the contractor logistics support system is not normative. There is no a set of effective and reasonable and standardized support mode to support the operation and maintenance of UAS, thus causing the operational readiness of UAS is not high, and wasting a lot of manpower and material resources in maintenance process, which greatly restricts the operation and development of UAS.

\section{The support features of MALE UAS under the mode of military trade}

\subsection{Requirement of user changes quickly}

In recent years, UAV technology has been developing rapidly, and its application in the actual war is also increasing. UAS equipment has become an increasingly popular product imported by foreign countries through the military trade. In the military trade market, with the rapid development of UAS, there is a fast change in the demand of user. Changing 
demands often force immature systems to be redesigned to meet new operational needs. Rapidly changing technology and economic conditions affect the ability of UAS to meet the specified reliability, maintainability and affordability requirements.

\subsection{The use frequency of UAS increases gradually}

The UAS have expanded from a single reconnaissance to a variety of uses in a short few decades, and have a tendency to become a future major weapon in the war. From the view of practical application, the use of UAS is becoming more and more frequent. The increasing use frequency is more urgent for the rationality and operability of the UAS support mode.

\subsection{Different countries deploy UAS with different status}

Due to the military products export to more than one country, the contractor needs provide different status UAS according to the different demands of different countries. Therefore, the contractor should arrange different maintenance support program and supply different support resources according to different support needs of many countries. This is a challenge to the support engineering management of contractor.

\subsection{The information chain between contractor and user is long}

As a special product in the market, military trade product must pass the military trade company, sometimes through intermediaries. Military trade products may go through several or even dozens of links from contractor to user, the length of information chain is long. It spends much time on arrival of requirement change from user to contractor, and there is a risk of unobstructed information. That makes it difficult for contractor to meet the support needs of user in a timely manner, causing the user can't use UAS to perform mission of reconnaissance and strike.

\subsection{Distributed deployment mode of UAS}

Compared to manned aircraft, it is extra necessary to deploy and support the ground station. The UAV, Ground Control Station (GCS), Ground Data Terminal (GDT), and Satellite Ground Data Terminal (SGDT) have the characteristics of distributed deployment and flexible configuration. Due to the need for operational tasks, not all ground stations are placed in the same site, but distributed deployed. Therefore, the UAS needs to consider the maintenance and support of the ground stations distributed in various positions, which puts forward higher demand for the support system.

\section{The current status of support mode for MALE UAS}

Due to the above support features, the support mode of UAS having no top-level design and reasonable arrangement, it is difficult for current support mode to adapt to operation and maintenance of UAS. This chapter analyses the root of shortcoming and weakness.

\subsection{Two-maintenance level is difficult to supply the support resources in time}

Currently, the maintenance level of UAS is divided into two level: the operation level maintenance (O-level) located in the user military bases and deport level maintenance (Dlevel) located in the contractor country. The O-level is mainly responsible for replacement 
maintenance and preventive maintenance of UAS, including equipment inspection, LRU replacement and engine maintenance. The O-level maintenance is simple, and needs manpower with low skill level. The D-level is mainly responsible for the maintenance whose maintenance capability beyond O-level, including repairing faulty LRU, faulty SRU, and engine overhaul. The D-level maintenance is complex, and needs manpower with more professional engineering skill level. Once the failure happens, and it can't be repaired at the O-level, the fault LRU need to be returned to the D-level to repair.

Under the mode of military trade, the transportation of device needs to be carried out across borders. The transportation of repair parts and spare parts is not as fast and convenient as domestic transportation, causing the device can't be delivered on time. Once a device has a fault, it need to be transported from the supply ministry in military base to the supply ministry in headquarters, then transported to the country of the contractor, which often goes through thousands of kilometers away to return to the O-level, not only time consuming, but also can't support on time. Therefore, the current two-maintenance level can't meet the needs of the operation and maintenance of UAS.

In addition, according to two-maintenance level at present, the O-level deploy support equipment and tools which are used to repair faulty SRU and overhaul, but a small number of spare parts is deployed. Besides, the manpower in O-level don't have the capacity to repair SRU and overhaul, so that the utilization rate and satisfaction rate of support resources is low, resulting in the redundancy and waste of support resources.

\subsection{The operations and support departments of UAS are not proper}

At present, the operation and support organization of UAS are still in the form of the manned aircraft's, which are divided into three parts, namely, the operation department, the maintenance department and the weapon department. The maintenance department and the weapon department belong to the logistics wing of the Air Force Base.

The operation department has two positions including pilot personnel and task personnel. The pilot personnel are responsible for controlling, operating, using the UAV, including take off, flying to the target location, landing to the runway. At the same time, the task personnel are responsible for the operation of EO/IR, reconnaissance target, operation of fire control system and the launch of weapons.

The maintenance department has four positions including mechanic personnel, avionics personnel, weapon personnel and data link personnel. Mechanic personnel are responsible for the maintenance and support of structure, landing gear, power and fuel system. Avionics personnel are responsible for maintenance and support of avionics, airborne data link device and payload. Weapon personnel are responsible for loading and uploading the missile and bomb. Data link personnel are responsible for the operation and maintenance of the ground station.

The weapon department has a position for a weapon maintenance personnel. The weapon maintenance personnel are responsible for the testing, maintenance, support and EOB handling of the weapons.

It can be seen from the configuration of operation and support organization structure that there are many problems in the operation and maintenance of UAS.

- The operation and support organization can't carry out the joint test of the UAV, the ground station, the weapon system and payload system. Because the operation department is not involved in the maintenance activities of UAS, they present only during the mission, while the maintenance department don't have the skills to operate UAV and fire control system and payload. 
- Although the data link personnel are subordinate to the maintenance department, it is required to obey the command of the operation department during the mission. That cross-departmental management is abused in the implementation.

- The weapon personnel of maintenance department are only responsible for the loading and unloading the missiles and bombs, which is easier than other positions, which results in unreasonable workload allocation of maintenance and support.

To sum up, the operation and support organization at present is not suitable for the operation and support of UAS. We need to customize the appropriate organization according to the characteristics of UAS.

\subsection{The mode of contractor logistical support is not architectonical and normative, which can't support the UAS effectively.}

Contractor logistical support refers to that the contractor is responsible for maintenance and support of the military. That is, the traditional mode that user takes all the logistics support activities changes to the mode that part of the work outsourcing, which improve the support efficiency and capability with the help of external technology, talent and resources.

The current contractor logistical support has no completely reasonable system and standard. Many cases happen that user is on leading position. When encountered problems, the foreign military would turn to contractor for help and support. At the same time, the contractor logistical support system lacks of top-level design, often falling into a passive position, which is hard to meet and reply the foreign support demand on time.

Studying on establishment of contractor logistical support system can effectively improve the efficiency of the whole life management of UAS. The main body of contractor logistical support system is the contractor, and the work is focused on the stage of support period. Establishing a scientific and reasonable contractor logistical support system can better understand the foreign support requirements and quality in the process of operation. On the other hand, the foreign military can easily communicate to the contractor for advice, therefore having a positive impact on the design, manufacturing and initial support resources supporting of UAS, which has important significance for improving the support performance of UAS.

\section{Explore a new support mode of UAS}

Based on the support requirement of military trade mode, this chapter aims to optimize and improve the unreasonable support mode at present, and explore a set of support mode that can suitable for the operation and support of UAS.

\subsection{Configure the three-maintenance levels of UAS}

In the mode of military trade, the maintenance level of UAS can't directly copy twomaintenance level of US Army. Because the industrial level and maintenance capability of user are often not satisfied to the requirements of UAS, so the D-level maintenance organization can't be established in user country. And the D-level still needs to be deployed in contractor country. On the other hand, in order to ensure the operational readiness and mission success rate of UAS, user still needs maintenance capability to a certain extent, so it is necessary to establish the I-level with maintenance capability that more than the Dlevel in headquarters or the centre of multinational force, including the replacement of fault SRU, simple direct maintenance, engine overhaul, and so on. Three-maintenance level as shown in Figure 2.

The establishment of three-maintenance level of UAS under the military trade mode can greatly reduce the time and distance of the faulty parts and spare parts in transport, it can 
effectively improve the supply capacity of spare parts and ensure the operational readiness and attendance rate of UAS.

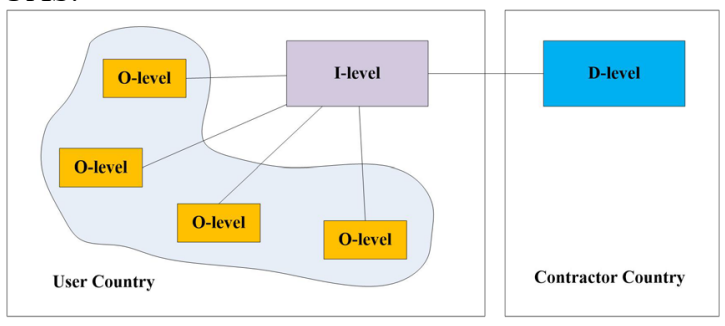

Fig. 2. Figure with three-maintenance level.

\subsection{Adjust the organization structure of operation, maintenance and weapon department}

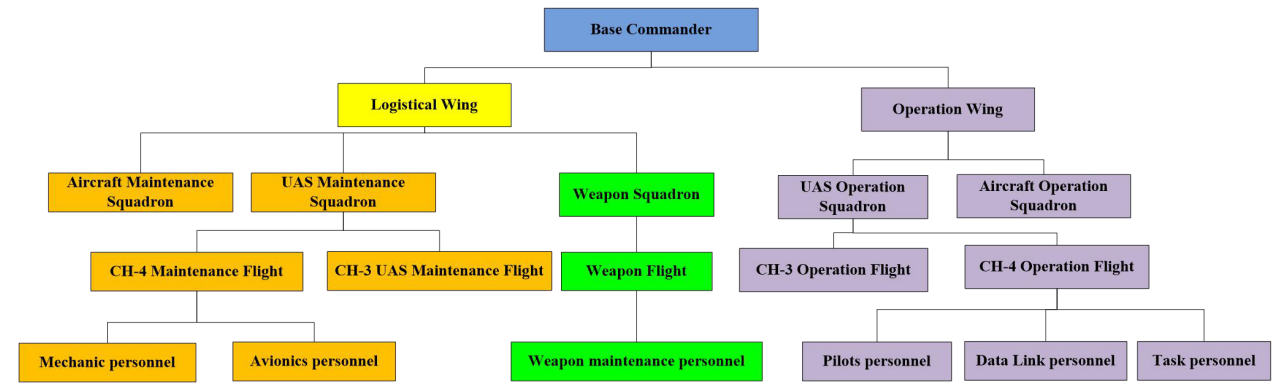

Fig. 3. Figure with adjustment of operation, maintenance and weapon department.

\subsubsection{The adjustment of operation department}

According to the current operation and maintenance organization, the data link personnel is removed from maintenance department to operation department, which is responsible for operation of data link in tasks. In this way, pilot personnel, task personnel and data link personnel are uniformly under the management and command of operation department, and complete the pre-flight and post-flight support activities with maintenance department and weapon department. After UAS takeoff, operation department performs the mission, maintenance department and weapon department are ready at the base. After the mission, personnel of operation department leave ground station.

\subsubsection{The adjustment of weapon department}

Weapon maintenance personnel of weapon department take over the job of loading and uploading the missiles and bombs from weapon personnel of maintenance department, and they should add the skills of operating the payload and fire control in ground station.

\subsubsection{The adjustment of maintenance department}

Data link personnel and weapon personnel will be cancelled; the mechanic personnel and avionics personnel will be reserved. The mechanic personnel need to increase skills of the maintenance and support for mechanical part in ground station; The avionics personnel need to increase the skills same as data link personnel and pilot personnel so that it can 
carry out the joint test of UAV, ground station and payload. The adjustment of operation, maintenance and weapon department as shown in Figure 3.

In this way, the three departments have clear labour and clear responsibilities. Operation department is responsible for the task execution. Maintenance department is responsible for the maintenance of UAV and ground stations on the ground. Weapon department is responsible for the maintenance and load and upload of the weapons.

\subsection{Build the contractor logistics support system of UAS}

In the mode of military trade, when users purchase UAS, they will sign 1-3 years of logistics support period. In the logistics support period, the maintenance and support of UAS are all organized and finished by the contractor logistical support team. In the middle and later period, the maintenance and support of UAS will be gradually turned over to user coordinated with contractor logistical support team.

According to the different responsibilities of contractor logistical support, it can be divided into training support activities, maintenance support activities, resources support activities, data support activities, as shown in figure 4 .

\subsubsection{Training support activities}

Training support activities refer to the technical education training to user by contractor before delivery for the first time and when the change of technology status, in order to make user understand the content of product performance, structure, working principle and maintenance requirements, so they can correctly operate and support UAS. Training support activities mainly provide training support equipment, training teachers, training courses, question bank of theory and practical exercises for foreign parties

\subsubsection{Maintenance support activities}

Maintenance support activities refer to that the contractor support team will be sent to base and guide the user to complete the maintenance and support of UAS. The main contents are as follows: 1) undertake or direct the installation, commissioning and maintenance and training of UAS; 2) provide technical advice related to UAS; 3 ) solve the quality problems of UAS in the transport, storage, operation and maintenance. When UAS is first equipped with the foreign forces, the technical service is generally needed.

\subsubsection{Resources support activities}

Resources support activities refer to that the contractor provide the necessary support resources including support equipment, support tools, spare parts and consumables, technical manuals to meet the support requirement of the foreign forces in wartime and peacetime training. After the delivery of UAS, the contractor should provide the spare parts based on reliability, maintainability, number and location of UAS to meet the requirement of maintenance, troubleshooting and turnover.

\subsubsection{Data support activities}

Data support activities refer to that the contractor collects the support data from missions and support activities, and analysis the indicators such as operational readiness, availability, mission success rate, attendance rate, resource utilization rate and satisfaction rate. So, it 
can identify the weak link of operation and maintenance of UAS, and provide data support for logistical support.

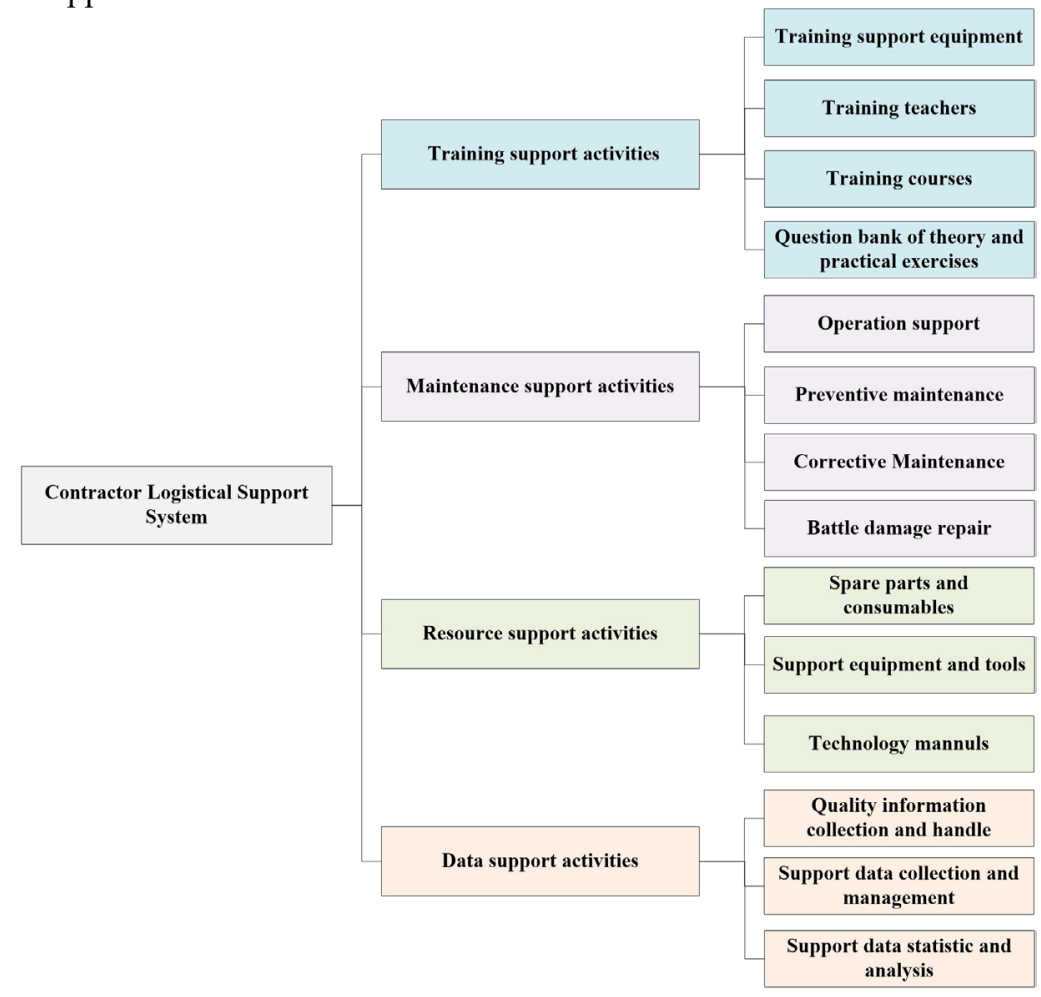

Fig. 4. Figure with Contractor Logistical Support System.

\section{Summary}

This paper sums up the support features of UAS under the military trade. As the same time, this paper analyses the status of the redundant and inefficient support mode which can't support the UAS effectively. Aiming at these problem, a new support model of UAS is researched from three aspects including the allocation of maintenance level, the adjustment of maintenance organization structure, and the establishment of contractor logistical support system. By applying the new support mode to user, the operation and support of UAS will be more effective and reasonable which will greatly promote the development of UAS.

\section{References}

1. Tang minfeng 2017 Support Characteristics and Development Trend of Military UAV Engine Aviation Maintenance \& Engineering 04 38-40

2. Cheng xin and Wang yongtao 2017 Research on the framework and development plan of maritime safeguard system on the base of unmanned aerial vehicle system China Maritime Safety 07 49-51

3. Liu yibiao, Xu gan, Yuan ye 2015 Public Communication of Science \& Technology 15 96-98

4. Qiao zhenlei and Shi xudong 2016 Research on the Depot-Level Maintenance Mode of UAV System Aviation Maintenance \& Engineering 06 35-37 